\title{
Design and Implementation of Digital Education Resources Blockchain Based Authentication System
}

\author{
Tri Wahyuningsih ${ }^{1}$, Gunawan ${ }^{2}$, Fitra Putri Oganda ${ }^{3}$, Mey Anggraeni ${ }^{4}$ \\ University of Raharja $1,3,4$, Universitas Sangga Buana ${ }^{2}$ \\ Jl. Jenderal Sudirman No.40, RT.002/RW.006, Cikokol, Kec. Tangerang, Kota Tangerang, \\ Banten 15117, Indonesia1,3,4 \\ Jalan PH.H. Mustofa (Suci) No.68, Cikutra, Kec. Cibeunying Kidul, Kota Bandung, Jawa Barat \\ $40124^{2}$ \\ e-mail: triwahyuningsih@raharia.info' ${ }^{1}$, gunawan@usbypkp.ac.id² ${ }^{2}$, fitra.putri@raharia.info3 ${ }^{3}$, \\ mey.anggraeni@raharia.info ${ }^{4}$
}

Wahyuningsih, T., Gunawan, Putri Oganda, F., \& Anggraeni, M. (2021). Design and Implementation of Digital Education Resources Blockchain-Based Authentication System. Blockchain Frontier Technology, 1(01), 74-86. Retrieved from

DOI: https://journal.pandawan.id/b-front/article/view/19

\begin{abstract}
With the approaching of the digital age, digital education resources bring convenience to folks as a result of they're liable to duplicate and spread, however there are some disadvantages in on-line education service transactions. The safety problems with digital education resources and also the development of smuggled distribution seriously harm the rights and interests of the house owners of digital education resources. supported this, during this paper, we have a tendency to planned a blockchain-based digital education resources authentication system that uses the decentralized, tamper-resistant options of blockchain technology to store the digital education resources info within the style of a secret text. Within the system, there is no have to be compelled to need the participation of any third-party institution. The system planned during this study can greatly defend the rights and interests of the owner of digital education resources.
\end{abstract}

Keywords: Educational Resources, Authentication System, Digital Education.

\section{Introduction}

In 2015, the State Council issued a series of "Internet +" connected policies to encourage academic enterprises and IT firms to supply on-line education services, develop digital educational resources and explore new models of online education services [1]. However, digital education resources face new issues that the utilization of it's seemingly to trigger disputations attributable to the convenience of digital education resource dissemination [2]. At an equivalent time, because of the infringements are exhausting to track, in addition to the wide selection of communication channels, leading to the digital education resources infringing problems are getting additional and more serious. Within the method of education service transaction, digital education resources were abused by amerciable merchants, that seriously affected the rights and interests of its owners. Therefore, it's imperative to relinquish a reliable and operational authentication methodology for digital education resources from a technical purpose of reading to appreciate the authentication of the possession of digital education resources [3]. At present, the authentication method supported by a centralized authority establishment is straightforward to be tampered with and defrauded, and it is troublesome to ensure the safety of the tutorial resources information of the education service transaction. The blockchain technology is a distributed ledger technology or ledger system and it uses a 
suburbanised infrastructure and distributed storage accord technology to firmly store dealings data. The pool blockchai is semi-public and multi-centralized, that may be a blockchain employed by many institutions [4]. Its block node is chosen at intervals the organization, and therefore the addition and deletion of nodes on the blockchain are determined by the consortium blockchain consensus mechanism. victimization consortium blockchain simplifies the authentication method and permits for quicker transaction speed, which reduces transaction prices to an explicit extent [5]. Within the consortium blockchain, solely the consortium members will scan and write the data, which might be wont to defend the non-public data and make sure that the information doesn't tamper [6].

In this paper, we tend to style and implement a blockchain-based digital education resources authentication system for the matter of the authentication of educational resources. In our system, resource authentication means that to determine the owner of the resource and resource access. Initial of all, we designed the good contract, then we designed the functions of every module in step with the system requirement [7]. Finally, the particular check proves that the system will effectively understand the method of uploading and authenticating digital resources. supported the blockchain technology, it's attainable to effectively guarantee the academic resources info from being tampered and realize the authentication of digital education resources, and shield the legitimate rights and interests of its owners [8].

\section{Research Method}

The blockchain construct has attracted widespread attention since it had been introduced in Bitcoin: A peer-to-peer electronic money system. The blockchain technology relies on distributed infrastructure, which may notice the distributed knowledge storage. The blockchain technology uses some distributed nodes to come up with and update data, uses cryptography to secure data transmission and access, and uses smart contracts to constrain and manipulate data [9]. A sensible contract is an agreement which will be dead automatically. Automatable by computer, though some components may need human input and control. enforceable either by legal social control of rights and obligations or via tamper-proof execution of coding system. If we have a tendency to use blockchain and style sensible contracts to resolve the authentication drawback of digital education resources, the system doesn't need the superintendence of authority establishments or sure third parties, and digital education resources possession data is held on a distributed network of multiple nodes [10]. The blockchain technology will effectively cut back fraud by guaranteeing that knowledge within the system is clear and managed in a very suburbanized manner [11]. The blockchain technology conjointly incorporates a comparatively high fault tolerance that is supported by several distributed nodes, and every of the taking part nodes in the system has a copy of the total ledger. Although there are some service anomalies in many nodes, the entire system will still guarantee traditional operation, allowing the system to supply reliable technical support furthermore because of the info redundancy center [12].

Currently, the blockchain are often divided into 3 forms betting on the applicable scenario: personal blockchain, association blockchain, and public blockchain. Among them, the members within the consortium blockchain will be a part of and exit the blockchain network through authorization, that has higher quality than the general public chain, whereas creating up for the deficiency that the private blockchain is just receptive people [13]. so as to push crossindustry blockchain technology, the Hyperledger project was established by the UNIX operating system Foundation and also the Hyperledger cloth is one in every of the blockchain comes in Hyperledger, which may be a platform for distributed ledger solutions with a standard design that gives high confidentiality, flexibility, and measurability. cloth provides the grpc API and also the SDK for the higher application[14]. Applications will access the general public ledger in association blockchain by interacting with genus Apis and SDKs. Events within the system are often accessed by the applications, and trigger alternative external systems. The process logic of dealings is dead by the good contract. This text programs the smart contract and packages the business logic and releases it to the nodes of the material network. The material has the characteristics of quick transaction rate and scalability that fully meets the business needs. So, 
this paper chooses to use cloth as a technical resolution to comprehend the corresponding business model [15].

\section{The Design Of Digital Education Resources Authentication System Based On Blockchain \\ 3.1 The Design of System Architecture}

The traditional authentication system usually uses a shopper/server design. completely different from the standard application, the blockchain-based digital education resources authentication system could be a system that established on the blockchain network, which has the benefits of decentralization, secure storage, dealing traceability, anti-tampering and then on. supported the blockchain technology, this paper styles a digital education resources authentication system [16]. In our system, the client solely has to calls API to move with the net browser while not requesting access to the centralized server. The system architecture of the paper is planned consistent with the Hyperledger material framework of pool blockchain IBM [17]. The overall design is shown in Figure 1.The system is split into 3 parts, the highest layer is that the application layer, that in the main achieves the functions of registration, login, academic resource uploading, educational resource possession info authentication, and administrator management [18].

The middle layer is that the good contract layer, that primarily realizes the corresponding business process logic of the system [19]. The bottom layer is that the fabric network layer, wherever every node forms a node network with equal rights and obligations through the P2P protocol, that uses the agreement mechanism to attain consistency [20]. P2P, a replacement network technology that depends on the computing power and information measure of the participants within the network, instead of reckoning on some servers, can do decentralization. The material network layer is employed to simply accept dealings verification, generate a knowledge block, give question the possession of digital education resources, and store all academic resource data in the blockchain [21]. 
Digital Education Resources Authentication System

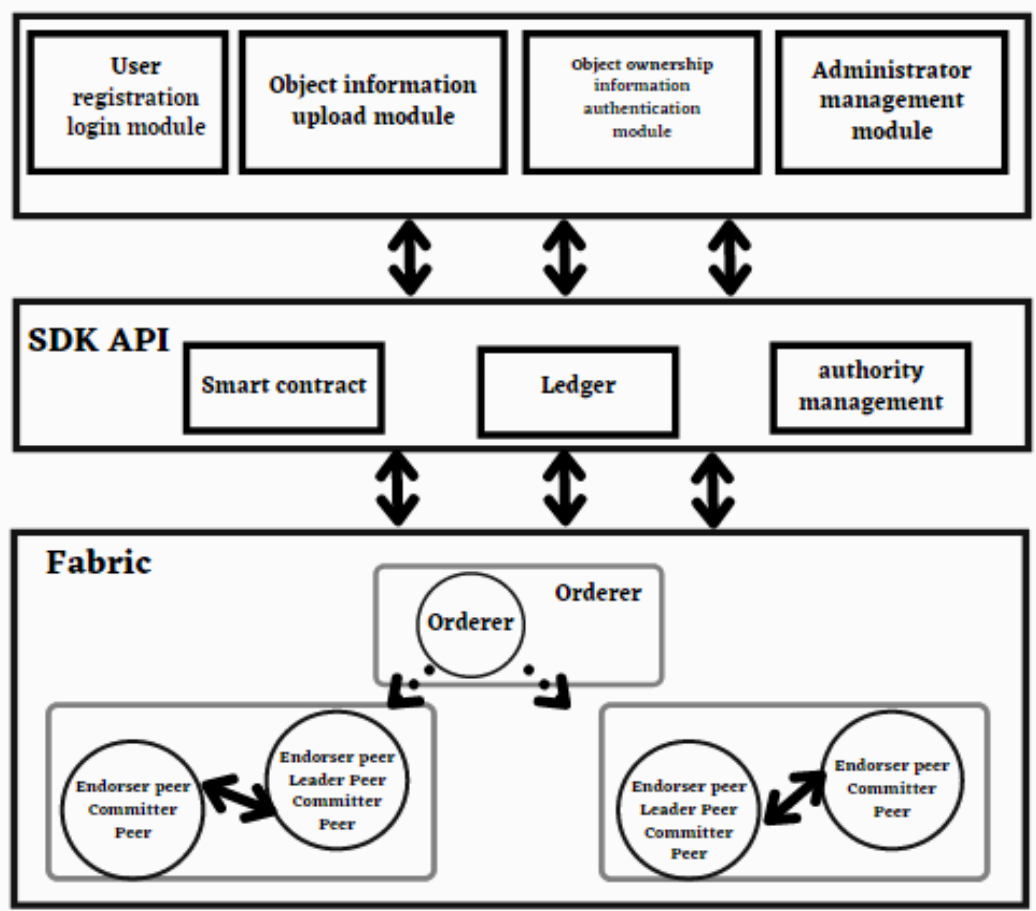

Figure 1. Digital Education Resources Authentication System Architecture

\subsection{The Design of Smart Contract}

This paper chiefly introduces the sensible contract of the digital education resources authentication system from 3 aspects : participants, assets, and transactions. The participants are divided into directors and users, who will own assets or initiate transactions. every participant should have a novel symbol and alternative attributes will be included [22]. The user mainly uploads resources, further as downloads and uses it. the info structure of the user is intended as User=watchword, Name, Email, ResourceList\}, wherever the ID is that the users unique identifier, the Password is the user's login password, the Name is the users name, the e-mail is the users email address, and therefore the ResourceList is that the user-owned resource's ID. The assets that should have a novel symbol and add relevant data to associate participants consult with any tangible and assets and every one tradable commodities that may be hold on within the blockchain. The assets during this article refer to the digital education resources, whose arrangement is intended as Resource = produce time, type, ownerld $\}$, wherever the free is the resource's ID, name is the resource's name, the create time is the creation time of the resource, the sort is the resource's format type, the ownerld is that the owner's ID of the resource. within the blockchain network, transactions consult with the method by that the restserver interface invokes a wise contract [23].

The definition of the contract perform is shown in Figure 2. The function of the contract is as follows: registerAdmin() suggests that to register administrator account, registerUser() means to register user account, registerResource() means to transfer the academic resource, check() means to envision the user information, and query() means to question educational resource information, checkRight() means to look at the owner of educational resource [24]. 


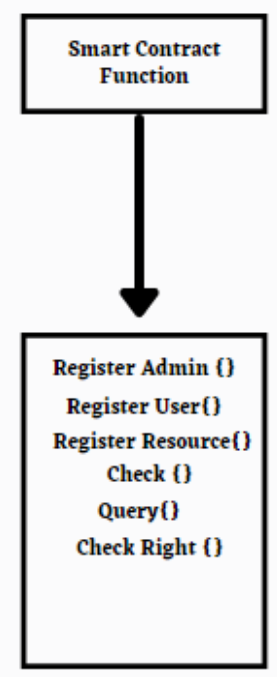

Figure 2. Smart Contract Function

\subsection{The design of Function Modules}

Digital education resources authentication system consists of multiple modules as well as user registration and login, digital education resources uploading, digital education resources possession info authentication, and administrator management. we tend to style the blockchainbased digital education resources authentication system, and therefore the specific authentication ways include: (1) exploitation the sensible contract to submit users' identity information to the blockchain, (2) using the smart contract to envision submission information, (3) using the smart contract to submit digital education resources information to the blockchain, and (4) using the smart contract to attain ownership authentication of digital education resources. Among them, we designed a info to ensure the timeliness \{of data|of knowledge|of info\} reading [25]. Once the resource information is submitted to the blockchain system, the resource is additionally recorded within the native database. The resource information storage methodology as shown in Figure 3. reckoning on the business needs, the blockchain-based digital education resources authentication system consists of the subsequent four modules [26]. 

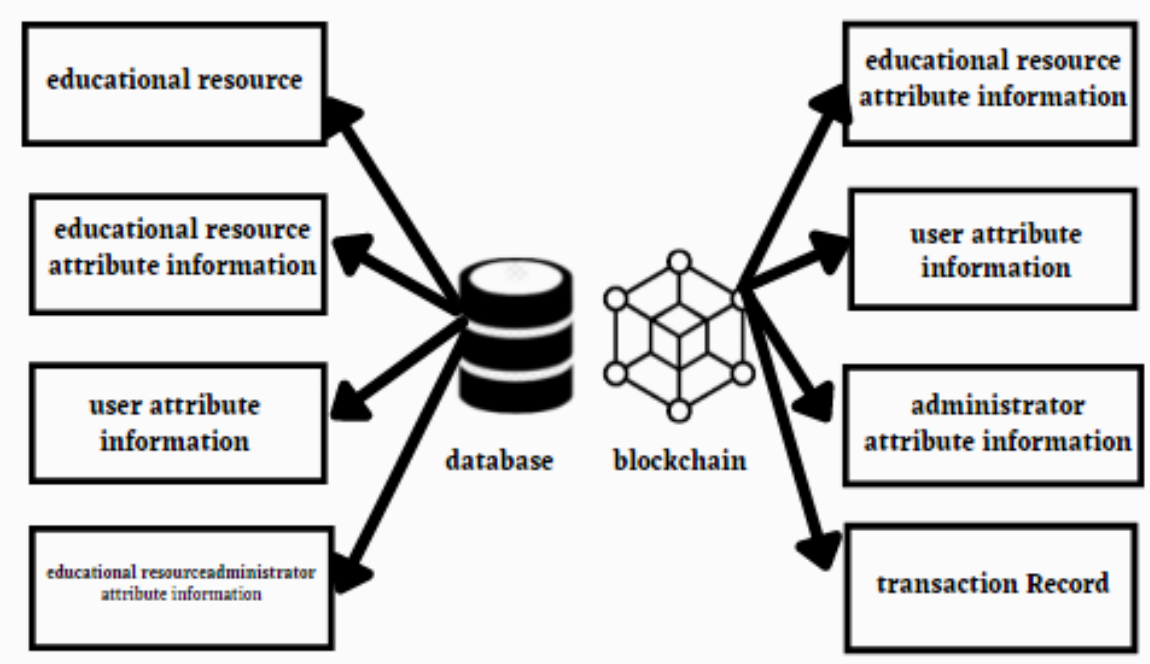

Figure 3. The Method of digital education resource information storage

\subsubsection{User registration and login module}

By job the good contract to register a private account, the administrator reviews the registration data. If the administrator accepts the request, the user can complete registration. Otherwise, user registration fails, and therefore the registration information must be resubmitted. The users identity information is recorded on the blockchain through smart contracts to make sure the legitimacy of the information. job the smart contract, the user inputs the account and password, and if the identity comparison is successful, the login operate is completed [27].
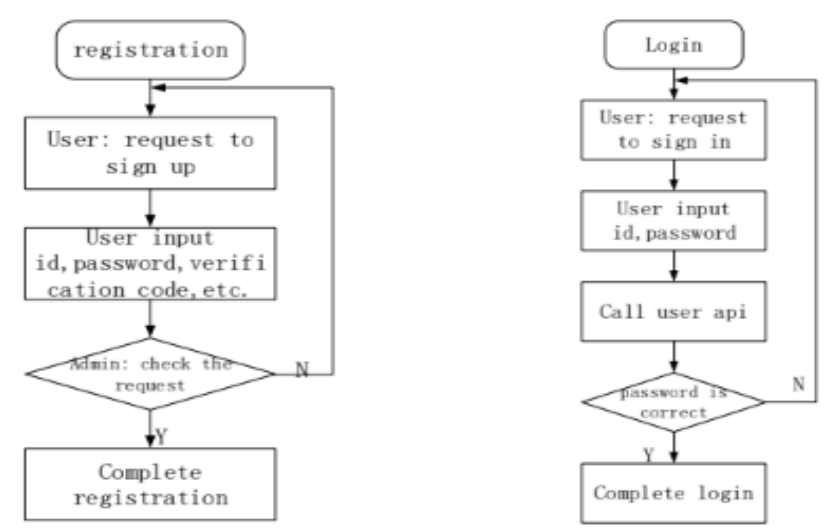

Figure 4. User Registration and Login Process

\subsubsection{Digital education resources uploading module}

By line the sensible contract to register a private account, the administrator reviews the registration data. If the administrator accepts the request, the user can complete registration. Otherwise, user registration fails, and also the registration information must be resubmitted. The users identity information is recorded on the blockchain through smart contracts to make sure the believability of the information. line the smart contract, the user inputs the account and password, and if the identity comparison is successful, the login perform is completed [28]. 


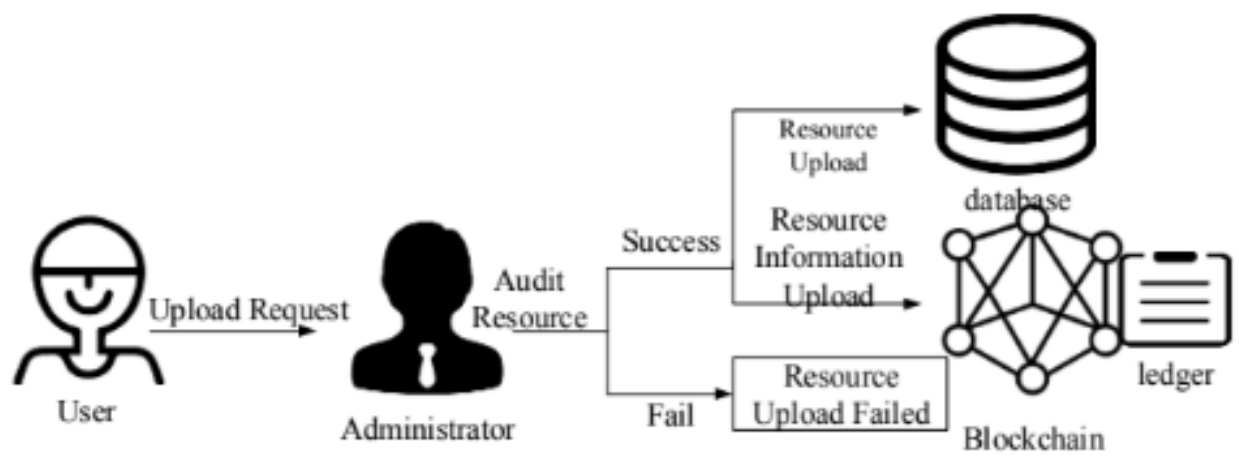

Figure 5. Digital Education Resources Upload Process

\subsubsection{Digital education resources ownership information authentication module}

When the user transfers or uses the academic resource, it's necessary to verify whether or not the user has the permission to download or use the resource. The system can question the relevant information keep within the blockchain network and database. The system calls a wise contract to execute information matching automatically. If the data matching is successful, the user will be allowed to download or use the resource, otherwise, the user can't download or use the resource. During this way, digital education resources authentication is completed [29].

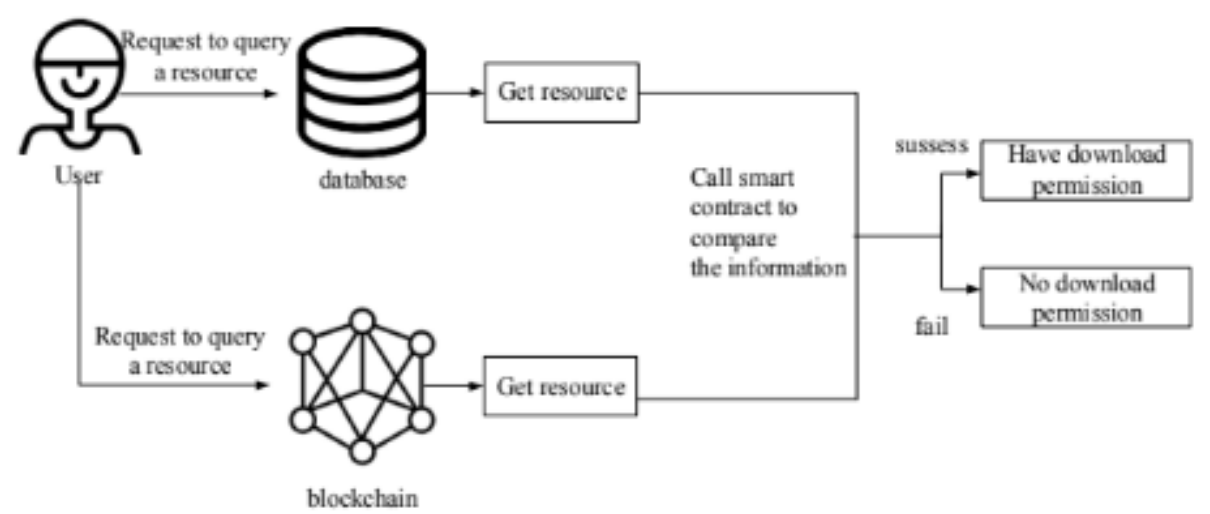

Figure 6. Digital Education Resources Ownership Information Authentication Process

\subsubsection{Administrator management module}

The relevant directors will read all users' personal information, the operation of the user, and review the running standing of the blockchain, and therefore the the contents of the digital education resources submitted by the user. At a similar time, the administrator also undertakes to supervise and ensure the implementation method of vital certifications cherish possession certification [30]. Once the user uploads an academic resource, the resource are going to be listed within the unaudited resources list; the administrator must verify the lawfulness of the resource before it's keep in the information and blockchain. If the resource is illegal, it'll be backed up within the file library that fails to pass the audit; otherwise, it's allowed to be stored, and also the user will acquire the resource data in our system.

\section{The Implementation Of Digital Education Resources Authentication System Based On Blockchain}


In this system, the material network is deployed on the Ubuntu system, victimisation hyperledger musician to develop and build the business model and utilizing composer-restserver to come up with the API of the business model. The purchasers implement specific perform modules through cross-process communication access to the interface. anytime the user submits the information, the dealing record is after prepacked into blocks by alternative nodes and recorded on the blockchain. Once the transaction record is keep within the blockchain, it cannot tamper [31].

\subsection{The Development Platform}

The system uses hyperledger musician to develop a business program supported cloth networks and completes the interaction between websites and blockchains. The blockchain network is supported by the fabric. First of all the system builds a business network on the Ubuntu 16.04 system. and so the composer interacts with the deployed business network to quickly develop good contracts through the composers modeling language and API. Finally, the system interacts with the blockchain network through composer-rest-server [32].

\subsection{The Implementation of Smart Contract}

The system in the main implements the relevant business logic by sensible contracts and uses musician to make a cooperative tool of the blockchain industrial network which might be quickly build. We have a tendency toan internetan online\} interaction interface. Within the composer, we implement smart contracts by writing relevant files that are cto file, js file, qry file, and acl file [33]. The cto file is employed to outline a business network model for assets, participants, and transactions; the js file is used to explain business logic; the qry file is used to supply question interfaces; the acl files define the permission rules. In step with the system requirements, the model file defines User ANd Admin as participants, Resource as an asset, and registerAdmin, registerUser, registerResource, CheckRight, query, and check, etc as dealings, and implements the outlined transaction business model by writing business logic. Finally, the composer-rest-server is wont to generate the remote interface of the business model to realize the sensible contract [34].

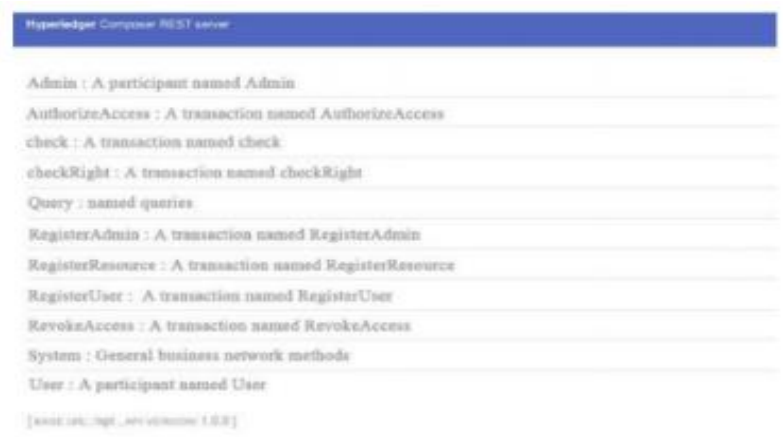

Figure 7 Composer-Rest-Server Interfacace

\subsection{The Implementation of Function Module}

\subsubsection{User Registration Login Module}

According to the system prompt, the user inputs the relevant info, so repeatedly inputs the countersign doubly to enhance the safety of your account. Once the system properly verifies the information, the RegisterUser API interface are known as to form the users information (id, password, name, mailbox, etc.) as a group action and mark the id because the standing to be 
confirmed. Once the administrator reviews the information, the transaction is broadcast to the blockchain network for verification to complete the user registration [35]. The registered user inputs the registration id and password information, and also the system calls the User API to match whether or not the knowledge you entered and also the account information hold on within the blockchain are consistent to complete the user login. The concrete realization impact is shown in Figure 8.
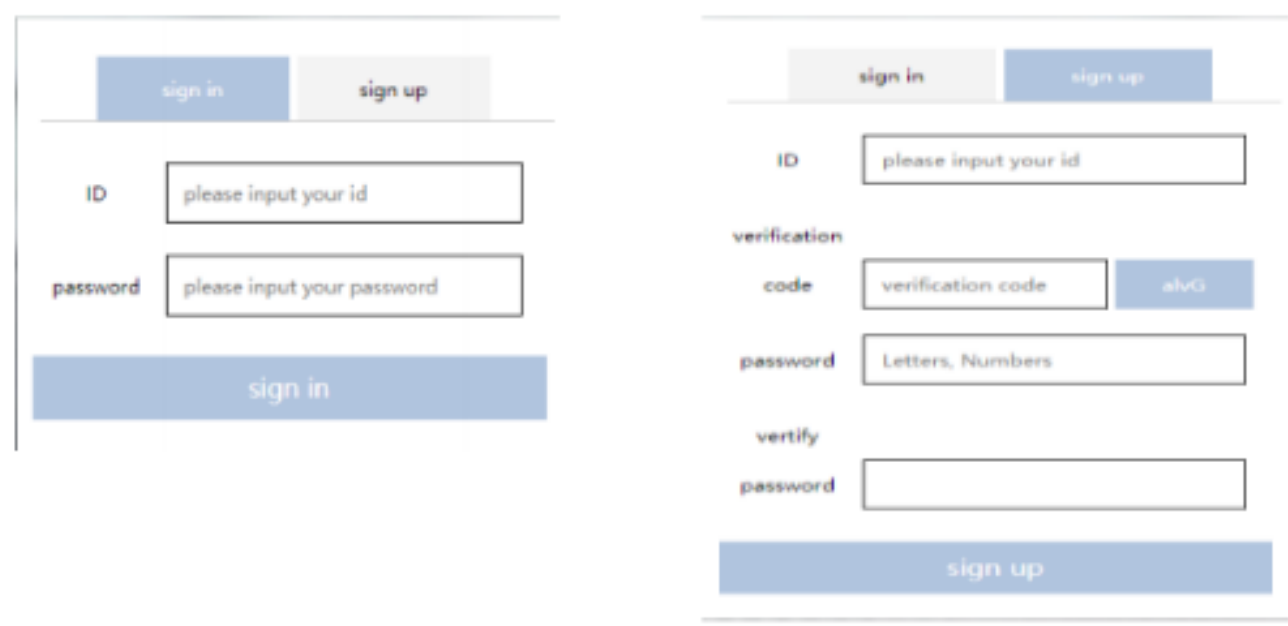

Figure 8. User Registration Login Effect

\subsubsection{Digital Education Resources Upload Module}

The user fills within the basic information of the resource and uploads the resource supply file. The system can decision the Resource API to make the outline information of the resource (id, name, creation time, resource owner id, etc.) into a transaction, watching for the administrator to verify [42]. Once the administrator completes the verification, the data of the resource is hold on into the blockchain. The resource source files and resource information are stored in the database. The resource uploading result is shown in Figure 9.

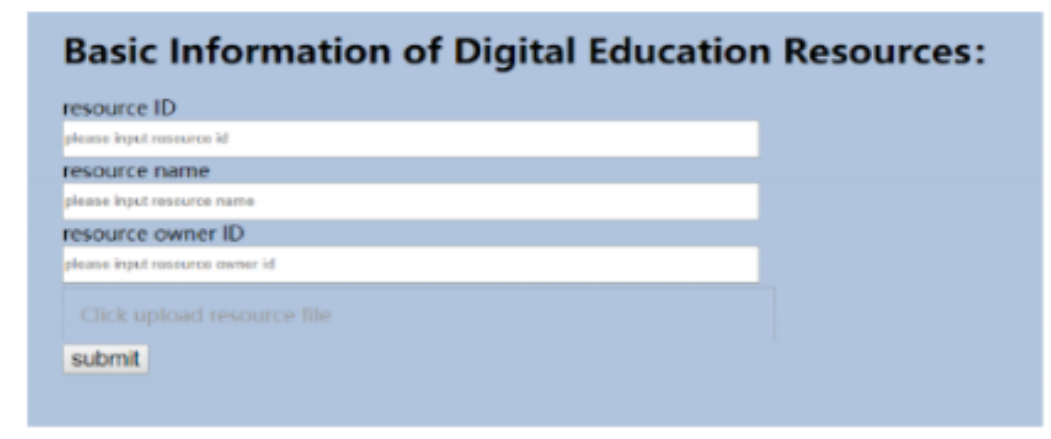

Figure 9. Resource Uploading Effect

\subsubsection{Education Services Transaction Subject Ownership Information Authentication Module}

When the user consults or transfers a resource, the system can question the relevant info that stores within the information and also the blockchain. If the resource is queried in the database, the system will query the resource owner id information in the blockchain. By line the CheckRight API, the system will check whether or not the user owns the resource, and if the 
verification is unsuccessful, the user cannot consult or download the resource [36]. The possession info authentication result is shown in Figure 10.

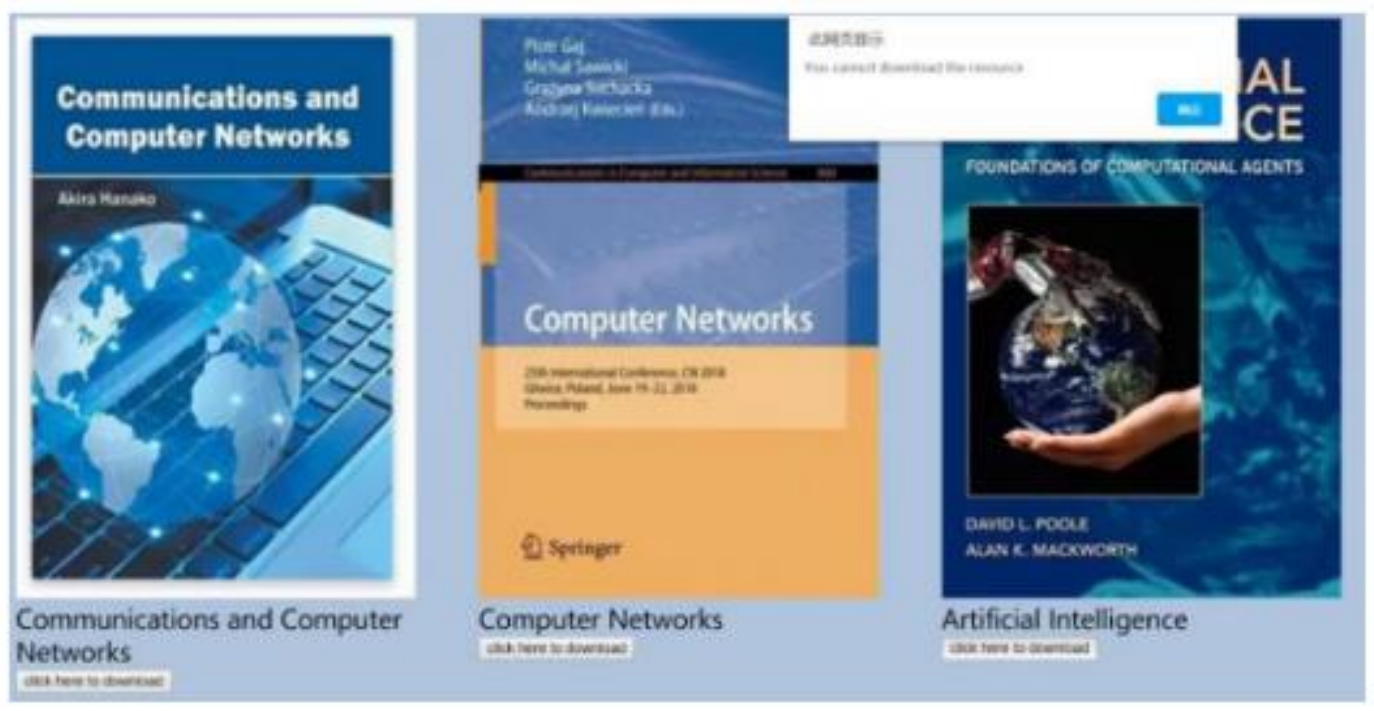

Figure 10. Resource Ownership Information Authentication Effect

\subsubsection{Administrator management module}

After the user uploads the resource supply file, the administrator queries the list of unaudited resources by career the question API, and also the system verifies the validity of the resource by calling the check API. If the resource is verified successfully, it'll be keep within the blockchain and database, otherwise, the audit will refuse the request [37]. The audit info result is shown the Figure 11.

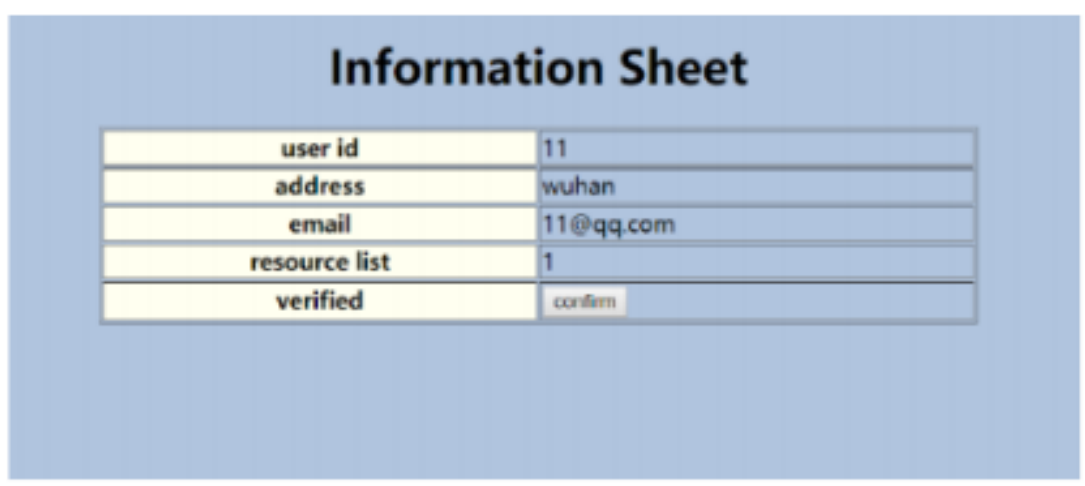

Figure 11. Administrator Audit Information Effect

\section{Conclusion}

At present, within the method of education service transaction, the resource possession data adopts the centralized management methodology that refers to the management mechanism verified by the centralized authority. The blockchain technology will give a localized ownership authentication method for digital education resources and guarantee the protection of the ownership information. supported this, this paper analyzes the present issues in the digital education resources ownership authentication, combined with the syndicate blockchain technology, styles a blockchain-based digital education resources authentication system which realizes the essential functions that contain resource information uploading, resource ownership information authentication and protects the owners' rights and interests of the resources. Compared with the normal authentication methodology, the blockchain-based authentication 
method ensures the non-tamperability of the resource possession data. The system mode we tend to planned may be applied to the educational Management System, academics transfer digital education resources, and students of the course will transfer the resource when the authentication, that defend the ownership information from tamper.

\section{References}

[1] Y. C. Chen and F. Basbeth, "Entrepreneurial Intention And The Moderating Role Of Gender Evidence From Ipmi International Business School In Jakarta," in Conference Series, 2020, vol. 3, no. 1, pp. 706-721.

[2] R. J. Sipahutar, A. N. Hidayanto, U. Rahardja, and K. Phusavat, "Drivers and Barriers to IT Service Management Adoption in Indonesian Start-up Based on the Diffusion of Innovation Theory," in 2020 Fifth International Conference on Informatics and Computing (ICIC), 2020, pp. 1-8.

[3] U. Rahardja, A. N. Hidayanto, N. Lutfiani, D. A. Febiani, and Q. Aini, "Immutability of Distributed Hash Model on Blockchain Node Storage," Sci. J. Informatics, vol. 8, no. 1, pp. 137-143, 2021.

[4] E. A. Sukma, A. N. Hidayanto, A. I. Pandesenda, A. N. Yahya, P. Widharto, and U. Rahardja, "Sentiment Analysis of the New Indonesian Government Policy (Omnibus Law) on Social Media Twitter," in 2020 International Conference on Informatics, Multimedia, Cyber and Information System (ICIMCIS), 2020, pp. 153-158.

[5] I. Faridah, F. R. Sari, T. Wahyuningsih, F. P. Oganda, and U. Rahardja, "Effect Digital Learning on Student Motivation during Covid-19," in 2020 8th International Conference on Cyber and IT Service Management (CITSM), 2020, pp. 1-5.

[6] U. Rahardja, N. Lutfiani, A. S. Rafika, and E. P. Harahap, "Determinants of Lecturer Performance to Enhance Accreditation in Higher Education," in 2020 8th International Conference on Cyber and IT Service Management (CITSM), 2020, pp. 1-7, doi: 10.1109/CITSM50537.2020.9268871.

[7] T. Hariguna, U. Rahardja, and A. Ruangkanjanases, "The impact of citizen perceived value on their intention to use e-government services: an empirical study," Electron. Gov. an Int. J., vol. 16, no. 4, pp. 426-440, 2020.

[8] U. Rahardja, S. Kosasi, E. P. Harahap, and Q. Aini, "Authenticity of a Diploma Using the Blockchain Approach,” Int. J., vol. 9, no. 1.2, 2020.

[9] U. Rahardja, Q. Aini, M. D. A. Ngadi, M. Hardini, and F. P. Oganda, "The Blockchain Manifesto," 2020, doi: 10.1109/ICORIS50180.2020.9320798.

[10] Q. Aini, S. Riza Bob, N. P. L. Santoso, A. Faturahman, and U. Rahardja, "Digitalization of Smart Student Assessment Quality in Era 4.0," Int. J. Adv. Trends Comput. Sci. Eng., vol. 9, no. 1.2, pp. 257-265, Apr. 2020, doi: 10.30534/ijatcse/2020/3891.22020.

[11] H. T. Sukmana, T. Hariguna, N. Lutfiani, and U. Rahardja, "Exploring the moderating effect of technology readiness of user intention in the context of mobile payment service," Int. J. Adv. Trends Comput. Sci. Eng., vol. 8, no. 1.5 Special Issue, pp. 249-257, 2019, doi: 10.30534/ijatcse/2019/4481.52019.

[12] S. Watini, Q. Aini, A. Khoirunisa, and U. Rahardja, "Assessment System for Testing the Evaluation of Diversity in Traditional Malay Dance by Early Childhood Students," Int. J. Psychosoc. Rehabil., vol. 24, no. 8, pp. 2721-2729, 2020, doi: 10.37200/IJPR/V24I8/PR280291.

[13] U. Rahardja, T. Hariguna, and Q. Aini, "Understanding the impact of determinants in game learning acceptance: An empirical study," Int. J. Educ. Pract., vol. 7, no. 3, pp. 136-145, 2019, doi: 10.18488/journal.61.2019.73.136.145.

[14] A. Suryadi, "The Implementation Of Turbine Ventilator As An Alternative Power Plant," ADI J. Recent Innov., vol. 2, no. 1, pp. 1-6, 2020.

[15] A. Suryadi, P. T. Asmoro, and A. Solihin, "Hybrid Electric Power Plant Using Wind Turbine Savonius Helix and Solar Cell as an Alternative Power Source in the Lightning Tower at Flashing Lights," ADI J. Recent Innov., vol. 1, no. 1 Sept, pp. 1-6, 2019.

[16] D. Royadi, N. Susiana, and F. A. Khumaida, "Effectiveness Management of Qualitative 
Research in Writing Scientific Papers," Aptisi Trans. Manag., vol. 3, no. 1, pp. 84-90, 2019.

[17] I. Noburu, A. Himki, A. Dithi, K. Kano, and M. Anggraeni, "Covid-19: Portrait of Preservation of the Batik Industry as a Regional Autonomy," Aptisi Trans. Technopreneursh., vol. 2, no. 2, pp. 143-152, 2020.

[18] U. Rahardja, Q. Aini, and A. Khoirunisa, "Effect of iDu (iLearning Education) on Lecturer Performance in the Lecture Process," Aptisi Trans. Manag., vol. 2, no. 2, pp. 140-148, 2018.

[19] U. Rahardja and T. Triyono, "Model Scheduling Optimization Workforce Management Marketing," Aptisi Trans. Manag., vol. 4, no. 2, pp. 92-100, 2020.

[20] V. A. Vieira, M. I. S. de Almeida, R. Agnihotri, and S. Arunachalam, "In pursuit of an effective B2B digital marketing strategy in an emerging market," J. Acad. Mark. Sci., vol. 47, no. 6, pp. 1085-1108, 2019.

[21] A. A. M. A. Ali, M. I. Dohan, and S. K. Musluh, "Denoising of image using bilateral filtering in multiresolution," 2017.

[22] P. A. Sunarya, Q. Aini, A. S. Bein, and P. Nursaputri, "The Implementation Of Viewboard Of The Head Of Department As A Media For Student Information Is Worth Doing Final Research," ITSDI J. Ed. Vol. 1 No. 1 Oct. 2019, p. 18, 2019.

[23] P. A. Sunarya, U. Rahardja, L. Sunarya, and M. Hardini, "The Role Of Blockchain As A Security Support For Student Profiles In Technology Education Systems," InfoTekJar J. Nas. Inform. dan Teknol. Jar., vol. 4, no. 2, pp. 13-17, 2020.

[24] S. Alfeno and D. Rifai, "Utilization of the Django Framework as a Dashboard Model Information System for Raw Material Inventory on PT Bimasakti Karyaprima," Aptisi Trans. Technopreneursh., vol. 1, no. 2, pp. 192-202, 2019.

[25] A. Philip, C. S. Putri, and P. M. Arifanggi, "Traffic Light Timer Control Using Raspberry Pi," Aptisi Trans. Technopreneursh., vol. 1, no. 2, pp. 134-143, 2019.

[26] E. Suryana, S. Syafnidawati, and D. Aryani, "Utilization Chart of Account For Effectiveness Company Cash Mapping On Web Based Accounting Online System 2.0," Aptisi Trans. Manag., vol. 1, no. 1, pp. 24-30, 2017.

[27] H. Haris and N. Priliasari, "THE DESIGN OF WEB-BASED TRAINING MANAGEMENT INFORMATION SYSTEMS AT PT. SINTECH BERKAH ABADI,” ADI J. Recent Innov., vol. 2, no. 2, pp. 269-274, 2020.

[28] S. Sudaryono, R. Rochmawati, N. Lutfiani, and U. Rahardja, "Strategy Enhancing Employee Reward Using the TOPSIS Method as a Decision Support System," IJCCS (Indonesian J. Comput. Cybern. Syst., vol. 14, no. 4.

[29] J. I. Saputro, I. Y. Hasibuan, and D. Octavia, "Information System Design Reminder Inventory Control At PT Nuansa Timur Lestari," Aptisi Trans. Manag., vol. 4, no. 1, pp. 49-56, 2020.

[30] M. Mardiana, N. Lutfiani, and R. S. Saga, "The Online Sales Application Of Black And White Print Based On Yii Framework On Higher Education E-Commerce Website," Aptisi Trans. Technopreneursh., vol. 1, no. 2, pp. 118-127, 2019.

[31] I. Setiawan, "Balinese Script In Tattoo Media Commodity In Denpasar Bali," ADI J. Recent Innov, vol. 1, no. 2, pp. 98-106, 2020.

[32] A. Muhtadibillah, H. T. Sukmana, and N. F. Rozy, "An Evaluation Of Helpdesk With Gamification Using Indeks Kepuasan Masyarakat (IKM)," IAIC Trans. Sustain. Digit. Innov., vol. 1, no. 1, pp. 8-17, 2019.

[33] Q. Aini, Z. Zaharuddin, and Y. Yuliana, "Compilation of Criteria for Types of Data Collection in Management of Research Methods," Aptisi Trans. Manag., vol. 2, no. 2, pp. 97-103, 2018.

[34] A. Williams and E. Dolan, "Application of Blockchain Technology in e-LoA Technopreneurship Journal," Aptisi Trans. Technopreneursh., vol. 2, no. 1, pp. 98-103, 2020.

[35] U. Rahardja, N. Lutfiani, and S. Amelia, "Creative Content Marketing In Scientific Publication Management In Industrial Era 4.0," Aptisi Trans. Manag., vol. 3, no. 2, pp. 168-178, 2019. 
[36] K. Rasyid and T. A. Pambudi, "Single-plate Swipe Couplings On Four-wheeled Vehicles," Aptisi Trans. Technopreneursh., vol. 2, no. 1, pp. 25-33, 2020.

[37] U. Rahardja, N. Lutfiani, and H. L. Juniar, "Scientific Publication Management Transformation In Disruption Era," Aptisi Trans. Manag., vol. 3, no. 2, pp. 109-118, 2019. 